\title{
Ketahanan Termal dan Ketahanan Perendaman Komposit NBR/EPDM dengan Berbagai Kompatibiliser
}

\section{The Thermal and Immersion Resistance of NBR/EPDM Composites with Different Compatibilizer}

\author{
Hesty Eka Mayasari \\ Balai Riset dan Standardisasi Industri Surabaya \\ Kementerian Perindustrian, J1. Jagir Wonokromo 360 \\ Surabaya, Indonesia \\ hesty.ekamayasari@yahoo.com
}

\author{
Noor Maryam Setyadewi \\ Balai Besar Kulit, Karet, dan Plastik \\ Kementerian Perindustrian, J1. Sokonandi no.9 \\ Yogyakarta, Indonesia \\ noormaryam@yahoo.com
}

\section{PEndahuluan}

\begin{abstract}
Abstrak - Komposit NBR/EPDM memiliki banyak manfaat, diantaranya sebagai sil, gasket. Ketahanan termal dan ketahanan terhadap perendaman perlu dipelajari untuk mengetahui kondisi penggunaan dan penyimpanan yang tepat. Dalam penelitian ini, komposit NBR/EPDM dicampur dengan berbagai kompatibiliser untuk mendapatkan komposit yang homogen, yaitu metil-metakrilat-butadiene-stirene (MBS), montmorillonite (MMT), dan silika. Komposit NBR/EPDM dibuat menggunakan two-roll mill dan divulkanisasi mengggunakan hydraulic press. Pengujian ketahanan termal dilakukan dengan menggunakan termogravimetry analyzer dan pengujian ketahanan terhadap perendaman dilakukan dengan metode perendaman dalam berbagai pelarut (IRM 903, toluene, n-heksana). Tujuan penelitian ini adalah untuk mengetahui pengaruh kompatibiliser terhadap ketahanan termal dan perendaman dari komposit NBR/EPDM. Dari penelitian diketahui bahwa kompatibiliser, khususnya MBS, dapat meningkatkan ketahanan termal hingga $2.5 \%$ dan ketahanan terhadap perendaman komposit NBR/EPDM hingga $2 \%$.
\end{abstract}

Kata kunci : Kompatibiliser, NBR/EPDM, perendaman, termogravimetri

Abstract- NBR/EPDM composites have many benefits, including as a seal, gasket. Thermal resistance and swelling resistance need to be studied to determine the proper conditions of use and storage. In this research, NBR/EPDM composites were blended with various compatibilizer to get homogeneous composites, namely methyl-methacrylate-butadiene-stirene (MBS), montmorillonite (MMT), and silica. NBR/EPDM composites were made using two-roll mill and vulcanized using a hydraulic press. Thermal resistance testing was carried out using a thermogravimetry analyzer and swelling resistance testing was carried out by immersion method in various solvents (IRM 903, toluene, n-hexane). The purpose of this study was to determine the effect of compatibilizer on the thermal and immersion swelling resistace of NBR/EPDM composites. The compatibilizer, especially $M B S$, can increase the thermal resistance up to $2.5 \%$ and swelling of NBR/EPDM composites up to $2 \%$.

Keywords : Compatibilizer, NBR/EPDM, immersion, thermogravimetry
Karet merupakan material yang sangat luas penggunaannya baik di industri maupun kehidupan sehari hari. Komposit karet merupakan campuran dari karet dengan karet lainnya maupun bahan aditif lain. Dalam penelitian ini akan digunakan karet sintetis, yaitu Nitrile Butadiene Rubber (NBR) dan Ethylene Propilene Diene Rubber (EPDM) sebagai matriks utama. NBR bersifat polar dan memiliki ketahanan yang baik terhadap minyak, oli. Namun NBR kurang tahan terhadap ozon maupun panas. EPDM merupakan karet yang cenderung non polar dan kepolarannya bergantung dari kandungan ENBnya (5-ethylidene-2-norbornene). EPDM memiliki ketahanan yang baik terhadap ozon dan panas, namun kurang tahan terhadap minyak dan oli ${ }^{[1,2]}$. Pembuatan komposit dari NBR/EPDM dapat meningkatkan sifat unggul dari kedua material tersebut ${ }^{[3]}$.

Dalam penelitian ini akan digunakan beberapa kompatibiliser dalam pencampuran karet NBR/EPDM, yaitu metil-metakrilat-butadiene-stirene (MBS), montmorillonite (MMT), dan silika. Perbedaan polaritas pada kedua karet tersebut sangat memungkinkan terbentuknya campuran yang tidak homogen, oleh karena itu kompatibiliser perlu ditambahkan dalam pencampuran NBR/EPDM ${ }^{[4,5]}$. MBS telah digunakan sebagai kompatibiliser NR/EPDM serta kompatibiliser karet dan plastik ${ }^{[4,6],}$ MMT telah digunakan untuk meningkatkan sifat mekanik dan termal NBR/SBR ${ }^{[7]}$, EPDM/silikon ${ }^{[8]}$, silika telah digunakan untuk meningkatkan sifat mekanik NR/NBR ${ }^{[9]}$.

Peningkatan sifat mekanik maupun termal dapat menunjukkan komposit yang dihasilkan telah homogen, sehingga matriks dan bahan pengisi terikat kuat dan ikatan silang yang terbentuk cukup baik. Penelitian mengenai campuran NBR/EPDM telah banyak dilakukan sebelumnya $[10,11]$, namun menurut pengetahuan penulis, belum ada penelitian secara spesifik mempelajari pengaruh kompatibiliser terhadap ketahanan termal dan perendaman komposit NBR/EPDM. Dalam penelitian ini akan dipelajari sifat ketahanan termal dan perendaman terhadap campuran NBR/EPDM dengan berbagai kompatibiliser. Karya tulis ini 
merupakan karya tulis kedua setelah sebelumnya pengaruh kompatibiliser terhadap proses vulkanisasi NBR/EPDM telah dipelajari ${ }^{[12]}$. Kompatibiliser yang tepat dapat membuat proses produksi menjadi efisien. Komposit NBR/EPDM dapat diaplikasikan untuk sil, gasket, lis. Oleh karena itu ketahanan termal dan perendaman ini perlu diketahui untuk mendapatkan informasi penggunaan dan penyimpanan yang tepat.

\section{BAHAN DAN METODE}

Bahan yang digunakan dalam penelitian ini antara lain NBR (Krynac 4975 F), EPDM (Keltan 4551 A, ENB 8.7\%) sebagai matriks utama. Carbon black jenis N330 High Abrassion Furnace (HAF) dan N774 Semi Reinforcing Furnace (SRF) (OCI, Korea) sebagai bahan pengisi, zinc oxide ( $\mathrm{ZnO}$, Indoxide) dan asam stearat Aflux $42 \mathrm{M}$ (Rhein Chemie) sebagai aktivator, parafin wax (Antilux 654 A) dan parafinic oil (Indrasari) sebagai anti oksidan, 6PPD (Starchem) sebagai anti ozonan, 2,2'-dithiobis(benzothiazole) (MBTS, Kemai) dan N-cyclohexyl-benzothiazylsulphenamide (CBS, Kemai) sebagai akselerator, PEG (PEG 4000 Korea), sulfur (Miwon) sebagai bahan pemvulkanisasi, serta methyl methacrylate-butadiene-styrene (MBS) (Huaxing), montmorillonite (Sigma Aldrch), dan silika (Zeosil 175P, Rhodia Silica Qingdao) sebagai kompatibiliser. Bahan-bahan tersebut dicampur dengan menggunakan two-roll mill, dan divulkanisasi dengan hydraulic press. Formulasi pencampuran ditunjukkan pada Tabel 1 seperti pada penelitian sebelumnya [12].

Tabel 1. Formulasi komposit NBR/EPDM

\begin{tabular}{|c|c|c|c|c|c|c|}
\hline \multirow{2}{*}{ Bahan } & \multicolumn{6}{|c|}{ Jumlah Bahan, phr } \\
\hline & $N_{10} E_{0}$ & $N_{0} E_{10}$ & $N_{5} E_{5}$ & $N_{5} E_{5} M$ & $N_{5} E_{5} M M T$ & $N_{5} E_{5} S$ \\
\hline NBR & 100 & 0 & 50 & 50 & 50 & 50 \\
\hline EPDM & 0 & 100 & 50 & 50 & 50 & 50 \\
\hline $\mathrm{ZnO}$ & 5 & 5 & 5 & 5 & 5 & 5 \\
\hline Asam stearat & 1 & 1 & 1 & 1 & 1 & 1 \\
\hline CB N330 & 30 & 30 & 30 & 30 & 30 & 30 \\
\hline CB N774 & 30 & 30 & 30 & 30 & 30 & 30 \\
\hline MBS & 0 & 0 & 0 & 2.5 & 0 & 0 \\
\hline MMT & 0 & 0 & 0 & 0 & 2.5 & 0 \\
\hline Silika & 0 & 0 & 0 & 0 & 0 & 2.5 \\
\hline PEG & 0 & 0 & 0 & 0 & 0 & 0.1 \\
\hline Parafinic Oil & 10 & 10 & 10 & 10 & 10 & 10 \\
\hline Parafinic Wax & 0.5 & 0.5 & 0.5 & 0.5 & 0.5 & 0.5 \\
\hline 6 PPD & 5 & 5 & 5 & 5 & 5 & 5 \\
\hline MBTS & 1.5 & 1.5 & 1.5 & 1.5 & 1.5 & 1.5 \\
\hline CBS & 0.5 & 0.5 & 0.5 & 0.5 & 0.5 & 0.5 \\
\hline Sulfur & 1.5 & 1.5 & 1.5 & 1.5 & 1.5 & 1.5 \\
\hline
\end{tabular}

Pengujian ketahanan termal dilakukan dengan metode termogravimetri menggunakan thermogravimetry analyzer Shimadzu DTG 60. Sampel pengujian sebanyak $10 \mathrm{mg}$ dari vulkanisat karet diletakkan pada alumina pan kemudian diuji menggunakan udara ambien dengan kecepatan $30 \mathrm{ml} / \mathrm{min}$ pada suhu $30-800{ }^{\circ} \mathrm{C}$ dengan kecepatan pemanasan $15{ }^{\circ} \mathrm{C} /$ menit. Massa yang tersisa akan ditunjukkan pada grafik termogravimetri dari software TA Instrument. Vulkanisat karet NBR/EPDM ditunjukkan pada Gambar 1.

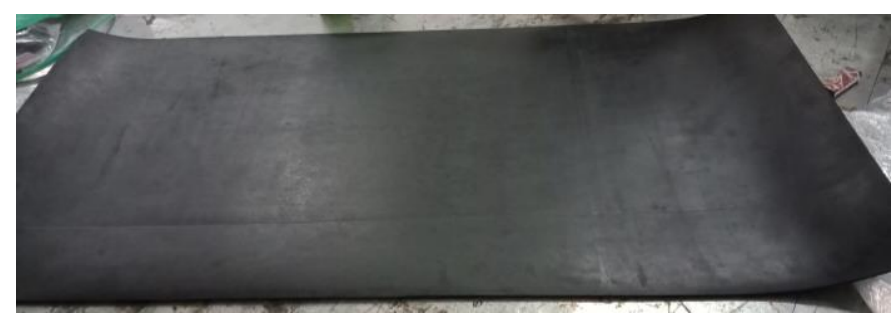

Gambar 1. Vulkanisat karet NBR/EPDM

Pengujian ketahanan terhadap perendaman dilakukan dengan menggunakan metode ISO 1817. Pelarut yang digunakan dalam penelitian ini adalah IRM 903, n-heksana, dan toluene. Ketahanan terhadap perendaman dinyatakan sebagai persentase swelling yang dapat dihitung menggunakan persamaan (1). Dimana adalah massa setelah perendaman dan adalah massa awal (g).

$$
\text { Swelling }(\%)=\left(\frac{w_{1}-w_{0}}{w_{0}}\right) \times 10
$$

\section{HASIL DAN PEMBAHASAN}

\section{A. Ketahanan termal}

Ketahanan termal komposit NBR/EPDM dipelajari dengan menggunakan metode termogravimetri. Metode termogravimetri ini mempelajari pengurangan massa terhadap kenaikan suhu. Ketahanan termal ini sangat penting untuk dipelajari untuk mengetahui karakteristik, kondisi penggunaan dan penyimpanan komposit. Grafik penurunan massa terhadap peningkatan suhu ditunjukkan pada Gambar 2 yang didapat dari hasil uji termogravimetri dengan alat thermogravimetry analyzer.

Grafik termogravimetri pada Gambar 2 menunjukkan dekomposisi termal suatu material. Massa komposit NBR/EPDM menurun seiring dengan kenaikan suhu. Ikatan antara matriks karet dan bahan aditif mulai terlepas dengan kenaikan suhu, sehingga material akan terdegradasi. Dalam dekomposisi termal, bahan aditif akan hilang pada titik didihnya. Tahap awal adalah penguapan kadar air, kemudian bahan aditif akan mulai terlepas dan selanjutnya terjadi degradasi material karet. Gambar 2 menunjukkan NBR dan EPDM mengalami dekomposisi termal yang lebih cepat dibandingkan dengan komposit NBR/EPDM, yang ditunjukkan dengan penurunan massa yang lebih awal (ditunjukkan dengan tanda panah). Hal ini menunjukkan bahwa komposit NBR/EPDM memiliki ketahanan termal yang lebih baik dibandingkan komposit NBR dan EPDM secara terpisah. Data dekomposisi termal komposit NBR/EPDM ditunjukkan pada Tabel 2. 


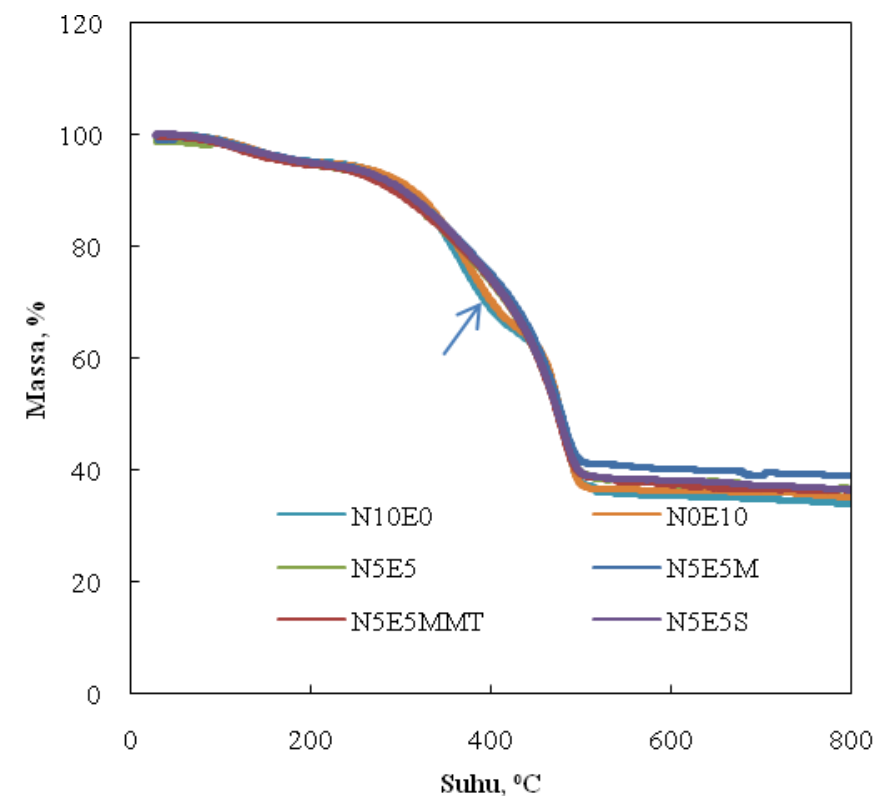

Gambar 2. Grafik termogravimetri komposit NBR/EPDM

Tabel 2. Dekomposisi termal komposit NBR/EPDM

\begin{tabular}{cccc}
\hline Komposit & $\begin{array}{c}\text { Suhu } \\
\text { dekomposisi, } \\
{ }^{\circ} \mathbf{C}\end{array}$ & $\begin{array}{c}\text { Suhu puncak } \\
\text { dekomposisi, } \\
{ }^{\circ} \mathbf{C}\end{array}$ & $\begin{array}{c}\text { Massa } \\
\text { terdekomposisi } \\
(\%)\end{array}$ \\
\hline $\mathrm{N}_{10} \mathrm{E}_{0}$ & $203-521$ & 471.96 & 66.08 \\
\hline $\mathrm{N}_{0} \mathrm{E}_{10}$ & $206-520$ & 480.44 & 64.86 \\
\hline $\mathrm{N}_{5} \mathrm{E}_{5}$ & $206-519$ & 472.45 & 63.63 \\
\hline $\mathrm{N}_{5} \mathrm{E}_{5} \mathrm{M}$ & $212-520$ & 476.29 & 61.16 \\
\hline $\mathrm{N}_{5} \mathrm{E}_{5} \mathrm{MMT}$ & $209-518$ & 473.02 & 63.61 \\
\hline $\mathrm{N}_{5} \mathrm{E}_{5} \mathrm{~S}$ & $210-517$ & 473.27 & 63.28 \\
\hline
\end{tabular}

Suhu dekomposisi, suhu puncak dekomposisi dan massa terdekomposisi didapatkan dari nilai yang ditunjukkan pada software TA Instruments. Suhu mulai dekomposisi menunjukkan suhu saat massa mulai berkurang. Pada suhu diatas $100^{\circ} \mathrm{C}$, massa mulai berkurang karena pengurangan kadar air, sehingga fase penguapan kadar air merupakan fase pre-dekomposisi. Tabel 2 menunjukkan bahwa seluruh komposit NBR/EPDM mulai terdekomposisi pada suhu diatas $202^{\circ} \mathrm{C}$. Hal ini menunjukkan bahwa komposit NBR/EPDM dapat digunakan hingga suhu $202{ }^{\circ} \mathrm{C}$ tanpa mengalami penurunan massa yang berarti. Suhu puncak dekomposisi menunjukkan suhu dimana massa yang hilang paling banyak. Sedangkan massa terdekomposisi menunjukkan massa yang hilang saat akhir pengujian $\left(800^{\circ} \mathrm{C}\right)$. Dari Tabel 2 diketahui bahwa seluruh kompatibiliser memberikan suhu dekomposisi awal dan suhu puncak dekomposisi yang lebih tinggi dibandingkan komposit tanpa kompatibiliser $\left(206^{\circ} \mathrm{C}\right.$ dan $472.45^{\circ} \mathrm{C}$ ). Seluruh kompatibiliser juga memberikan massa terdekomposisi yang lebih rendah dibandingkan komposit tanpa kompatibiliser $(63.63 \%)$. Hal ini menunjukkan bahwa kompatibiliser dapat meningkatkan ketahanan termal dari komposit NBR/EPDM. MBS sebagai kompatibiliser memberikan efek ketahanan termal yang paling baik. Hal ini dimungkinkan karena MBS merupakan material yang lapisan kulit intinya dimodifikasi dengan pencangkokan stirene (St) dan metil-metakrilat (MMA) pada partikel polibutadiena (PB) atau stirena butadiene rubber (SBR) ${ }^{[13]}$, sehingga dapat mengimprovisasi adhesi antar muka dari matriks karet dan bahan aditifnya. Hal ini membuat komposit lebih mudah menjadi homogen ${ }^{[14]}$. Kompatibiliser MMT yang merupakan material silikat dan silika memberikan hasil yang tidak terlalu berbeda karena memiliki kandungan unsur utama yang sama [15].

\section{B. Ketahanan terhadap perendaman}

Fenomena perendaman (swelling) penting dipelajari untuk mengetahui karakteristik komposit terhadap lingkungannya. Hasil pengujian ketahanan terhadap pelarut ditunjukkan pada Tabel 3. Dari pengujian diketahui bahwa NBR 100\% memiliki ketahanan terhdap pelarut yang paling unggul, baik dalam IRM 903, toluene, maupun n-heksana. Hal ini sesuai dengan penelitian sebelumnya yang menyatakan bahwa NBR memiliki ketahanan terhdap pelarut yang baik ${ }^{[1]}$. Sedangkan EPDM memiliki ketahanan terhadap pelarut yang kurang baik. Namun campuran antara NBR dan EPDM memberikan nilai ketahanan swelling yang lebih baik dari komposit EPDM.

Perendaman dalam IRM 903 memberikan nilai positif, yang berarti terjadi fenomena pembengkakan/ pengembangan (swelling) karet. Massa karet bertambah karena adanya difusi pelarut ke dalam matriks karet. Perendaman dalam toluene dan n-heksana menunjukkan nilai negatif yang menunjukkan fenomena penyusutan (shrinkage). Massa karet berkurang karena ikut terlarut dalam pelarut. Perbedaan fenomena ini terjadi karena perbedaan jenis pelarut. IRM 903 merupakan jenis oli, toluene merupakan pelarut aromatik, dan n-heksana merupakan pelarut alifatik. IRM merupakan pelarut polar sedangkan toluene dan n-heksana merupakan pelarut nonpolar. Dalam penggunaan karet sebagai seal maupun gasket, fenomena penyusutan ini tidak diinginkan kerena dapat menyebabkan kebocoran.

Ketahanan terhadap perendaman yang dinyatakan sebagai persentase swelling ditunjukkan pada Tabel 3 yang didapatkan dari persamaan (1). Selisih berat awal sebelum perendaman dan berat akhir perendaman digunakan dalam perhitungan persentasi swelling. Komposit tanpa kompatibiliser menghasilkan nilai swelling sebesar $15.76 \%$ pada IRM 903, $14.89 \%$ pada toluene, dan $13.28 \%$ pada n-heksana. Sedangkan komposit dengan kompatibiliset MBS, MMT, maupun silika memberikan nilai swelling yang lebih kecil. Hal ini menunjukkan kompatibiliser dapat meningkatkan ketahanan terhadap perendaman. Ikatan silang yang dihasilkan lebih rapat dan membuat free-volume pada matriks karet lebih sedikit, sehingga pelarut lebih susah menembus matriks tersebut. MBS memberikan nilai swelling yang paling kecil. Hal ini menunjukkan bahwa MBS memberikan campuran yang paling homogen karena dapat meningkatkan ikatan antara karet dan bahan aditifnya. 
Tabel 3. Persentase swelling komposit NBR/EPDM

\begin{tabular}{cccc}
\hline Kode & $\begin{array}{c}\text { IRM 903 } \\
(\%)\end{array}$ & $\begin{array}{c}\text { Toluene } \\
(\%)\end{array}$ & $\begin{array}{c}\text { N-heksana } \\
(\%)\end{array}$ \\
\hline $\mathrm{N}_{10} \mathrm{E}_{0}$ & 0.175 & -7.83 & -5.66 \\
\hline $\mathrm{N}_{0} \mathrm{E}_{10}$ & 48.32 & -30.01 & -28.75 \\
\hline $\mathrm{N}_{5} \mathrm{E}_{5}$ & 15.76 & -14.89 & -13.28 \\
\hline $\mathrm{N}_{5} \mathrm{E}_{5} \mathrm{M}$ & 14.09 & -12.89 & -11.02 \\
\hline $\mathrm{N}_{5} \mathrm{E}_{5} \mathrm{MMT}$ & 14.35 & -12.93 & -11.23 \\
\hline $\mathrm{N}_{5} \mathrm{E}_{5} \mathrm{~S}$ & 14.35 & -13.1 & -11.98 \\
\hline
\end{tabular}

\section{KESIMPULAN}

Komposit NBR/EPDM memiliki ketahanan termal dan ketahanan perendaman yang lebih baik daripada komposit NBR dan EPDM secara terpisah. Kompatibiliser MBS, MMT, dan silika dapat meningkatkan ketahanan termal komposit NBR/EPDM, yang ditunjukkan dengan meningkatnya suhu dekomposisi awal, suhu puncak dekomposisi serta tingginya massa yang tersisa saat akhir dekomposisi. MBS memberikan ketahanan termal terbaik dengan menurunkan massa terdekomposisi hingga $2.5 \%$ pada suhu pemanasan $800^{\circ} \mathrm{C}$. Komposit NBR/EPDM dapat digunakan sebagai sil atau gasket hingga suhu $200^{\circ} \mathrm{C}$. Kompatibiliser MBS, MMT, dan silika juga dapat meningkatkan ketahanan terhadap perendaman pada berbagai pelarut hingga $2 \%$. MBS adalah kompatibiliser yang paling sesuai untuk meningkatkan sifat ketahanan termal dan perendaman pada komposit NBR/EPDM.

\section{UCAPAN TERIMA KASIH}

Penulis mengucapkan terimakasih kepada Balai Besar Kulit, Karet, dan Plastik yang telah memfasilitasi penelitian ini dan BPPI Kementerian Perindustrian yang telah mendanai penelitian ini.

\section{DAFTAR PUSTAKA}

[1] H. E. Mayasari, N. M. Setyadewi, Effect of natural zeolite as substrate filler on the properties of NBR / EPDM blend, Maj. Kulit, Karet dan Plast., Vol. 35, No. 1, 2019, pp. 25-32.

[2] N. Ning, Q. Ma, Y. Zhang, L. Zhang, H. Wu, M. Tian, Enhanced thermo-oxidative aging resistance of EPDM at high temperature by using synergistic antioxidants, Polym. Degrad. Stab., Vol. 102, No. 1, 2014, pp. 1-8.

[3] H. E. Mayasari, I. Setyorini, A. Yuniari, The Blending of EPDM/NR with Maleic Anhydride as Compatibilizer: Comparing the Effect of Accelerators on Cure Characteristic and Mechanical Properties, Indones. J. Chem., Vol. 19, No. 1, 2019, pp. 106-114.

[4] H. A. Essawy, A. M. Khalil, M. E. Tawfik, S. H. El-Sabbagh, Compatibilization of NBR/SBR blends using amphiphilic montmorillonites: A dynamic mechanical thermal study, J. Elastomers Plast., Vol. 46, No. 6, 2014, pp. 514-526.

[5] M. Tavakoli, A. A. Katbab, H. Nazockdast, Effectiveness of maleic anhydride grafted EPDM rubber (EPDM-g-MAH) as compatibilizer in NR/organoclay nanocomposites prepared by melt compounding, $J$. Macromol. Sci. Part B Phys., Vol. 50, No. 7, 2011, pp. 1270-1284.

[6] Y. Liu, H. Li, Effect of the compatibilizers on polycarbonate (PC) /acrylonitrile-butadiene-styrene (ABS) blend Citation, Am. J. Mater. Res., Vol. 1, No. 3, 2014, pp. 48-52.

[7] M. E. Tawfik, S. H. El, Compatibilization of NBR / SBR blends using amphiphilic montmorillonites Journal of Elastomers, J. Elastomers Plast., Vol. 46, No. 6, 2014, pp. 514-526.

[8] V. Vijayalekshmi, A. M. S. S. M, Mechanical, Thermal and Electrical Properties of EPDM / Silicone blend Nanocomposites, Int. J. Eng. Res. Appl., Vol. 3, No. 2, 2013, pp. 1177-1180.

[9] C. Kantala, E. Wimolmala, C. Sirisinha, N. Sombatsompop, Reinforcement of compatibilized NR/NBR blends by fly ash particles and precipitated silica," Polym. Adv. Technol., Vol. 20, No. 5, 2009, pp. 448-458.

[10] V. Jovanović, S. Samaržija-Jovanović, J. Budinski-Simendić, G. Marković, M. Marinović-Cincović, Composites Based On Carbon Black Reinforced NBR/EPDM Rubber Blends, Compos. Part B Eng., Vol. 45, No. 1, 2013, pp. 333-340.

[11] H. E. Mayasari, N. M. Setyadewi, Thermogravimetry and Swelling Characteristics af NBR / EPDM Blends with Some Compatibilizers, AIP Conf. Proc., Vol. 020042, No. 2049, 2018.

[12] H. E. Mayasari, I. Setyorini, N. M. Setyadewi, Kemampuan Proses dan Karakteristik Vulkanisasi Campuran NBR/EPDM, J. Din. Penelit. Ind., Vol. 29, No. 1, 2018, pp. 19-28.

[13] L. Ren, M. Y. Zhang, Y. R. Wang, H. Na, H. X. Zhang, The Influence Of The Arrangement Of Styrene In Methyl Methacrylate/ Butadiene/ Styrene On The Properties of PMMA/SAN/MBS Blends, Polym. Adv. Technol., Vol. 25, No. 3, 2014, pp. 273-278.

[14] H. Nabil, H. Ismail, A. R. Azura, Optimisation of Accelerators and Vulcanising Systems On Thermal Stability Of Natural Rubber/Recycled Ethylene-Propylene-Diene-Monomer Blends, Mater. Des., Vol. 53, 2014, pp. 651-661.

[15] G. Hermenegildo, E. Bischoff, M. Giovanela, Development of Chlorobutyl Rubber/Natural Rubber Nanocomposites With Montmorillonite For Use In The Inner Liner Of Tubeless Ride Tires, $J$. Elastomers Plast., Vol. 49, No. 1, 2017, pp. 47-61. 